\title{
Analysis of Free Vibration of Hydraulic Opposing Cylinder Controlled by Servo Valve
}

\author{
Xiaoming Yuan ( $\nabla$ xiaomingbingbing@163.com ) \\ Yanshan University https://orcid.org/0000-0001-5779-1366 \\ Weiqi Wang \\ Yanshan University \\ Xuan Zhu \\ Yanshan University \\ Bing Du \\ Yanshan University \\ Lijie Zhang \\ Yanshan University
}

Original Article

Keywords: Hydraulic opposing cylinder controlled by servo valve, Transmission system, Free vibration, Natural frequency sensitivity, Modal test

Posted Date: September 28th, 2021

DOI: https://doi.org/10.21203/rs.3.rs-918845/v1

License: (c) (i) This work is licensed under a Creative Commons Attribution 4.0 International License.

Read Full License 
Title page

Nonlinear Dynamics of Hydraulic Opposing Cylinder Controlled by Servo Valve 
$\cdot 2 \cdot$

\section{Analysis of Free Vibration of Hydraulic Opposing Cylinder Controlled by Servo Valve}

Xiao-ming Yuan ${ }^{1,2,3} \cdot$ Wei-qi Wang ${ }^{1,2} \cdot$ Xuan Zhu $^{1,2} \cdot$ Bing Du ${ }^{1,2} \cdot$ Li-jie Zhang $^{1,2}$

Received June xx, 201x; revised February xx, 201x; accepted March xx, 201x

(c) Chinese Mechanical Engineering Society and Springer-Verlag Berlin Heidelberg 2017

\begin{abstract}
The fluid transmission medium has large compressibility and low rigidity, and its physical properties are extremely sensitive to state parameters such as flow, pressure and temperature. Therefore, compared with the mechanical transmission system, the natural frequency of the fluid transmission system is relatively low and has timevarying characteristics. After a wide frequency range changing of the load frequency and long-term operation, the excitation frequency of the fluid transmission system is more likely to approach its natural frequency and causes resonance, which seriously affects the normal operation of the system. Therefore, taking the hydraulic opposing cylinder controlled by servo valve as the research object, based on the analytical relationship between the dynamic bulk modulus and the equivalent stiffness of oil, the vibration dynamics models and equations of the system is established by using the lumped parameter method. Through the free vibration analysis, the natural frequencies and main vibration modes of the system are determined and the sensitivity changes of the natural frequencies to the design parameters are revealed. The maximum error between the theoretical modal frequency and the experimental one is $3.77 \%$, which verifies the correctness of

\footnotetext{
$\triangle$ Xiao-ming Yuan

xiaomingbingbing@163.com

1 Hebei Key Laboratory of Heavy Machinery Fluid Power Transmission and Control, Yanshan University, Qinhuangdao 066004, China

2 Key Laboratory of Advanced Forging \& Stamping Technology and
}

the dynamic model of the system. This research can provide a theoretical reference for the optimization of the dynamic performance of the hydraulic transmission system.

Keywords: Hydraulic opposing cylinder controlled by servo valve; Transmission system; Free vibration; Natural frequency sensitivity; Modal test

\section{Introduction}

The system of hydraulic opposing cylinder controlled by servo valve is a typical electro-hydraulic simulator. It has been widely used in aviation, aerospace, navigation and construction machinery and other fields with many advantages such as large power-to-weight ratio, wide frequency bandwidth, good stability and high reliability [14]. At present, there are two main factors restricting the further improvement of the dynamic performance of the electro-hydraulic simulator: (1) The working medium has large compressibility, small bulk modulus, low stiffness, and obvious mechanical nonlinear characteristics; (2) The change of state parameters such as flow and pressure of the fluid causes the movement and deformation of the load cylinder. Similarly, the movement and deformation of the load cylinder cause the fluid state parameters to change continuously. Thus, these two factors have mutual influence and mutual restriction, which causes the system has

Science, Ministry of Education of China, Yanshan University, Qinhuangdao 066004, China

3 State Key Laboratory of Fluid Power \& Mechatronic Systems, Zhejiang University, Hangzhou 310027, China 
mechanical-hydraulic coupling characteristics [5-7]. Low stiffness and mechanical-hydraulic coupling characteristics may cause the electro-hydraulic simulation hydraulic system to have large response deviations, system delay, working dead zone and nonlinear vibration, especially under wide frequency range changing of the load frequency and long-term operation. The excitation frequency of the system may be too close to its natural frequency to cause resonance, which will seriously affect the normal operation of the system [8-10]. Therefore, the free vibration analysis of hydraulic opposing cylinder controlled by servo valve is of great significance to improve the dynamic control accuracy and working stability.

Modal is the inherent property of mechanical system. Modal analysis is an analysis method based on vibration theory, which aims at modal parameter identification. Through modal analysis, the natural frequencies and corresponding modal modes of the system can be determined, in order to provide theoretical basis for the structural performance analysis, strain prediction and optimal design of the system [11-14]. Modal analysis methods are mainly divided into numerical simulation methods [15-17], experimental modal analysis methods [1819] and working modal analysis methods [20-23]. In the modal analysis of fluid, the coupling effect between the vibration of mechanical structures such as the internal pipe wall and the pressure pulsation makes the modal analysis of the fluid transmission system more complicated [24-25]. When establishing the dynamics model of a system with mechanical-hydraulic coupling characteristics and discrete continuous coupling characteristics, methods such as discretizing the continuum and equating the hydraulic actuation system as a linear spring can be used to reduce the difficulty of solving the coupled system dynamics problem [26-27].

In order to provide a theoretical basis for the dynamic optimization design of the system and improve efficiency, sensitivity analysis can be used to evaluate the degree of influence of each design parameter on the response of the system, which is an important index to measure the importance of each design parameter [28-30]. Sensitivity analysis has been widely used in power systems, hydraulic systems, mechanical design and other fields. Sensitivity analysis includes local sensitivity analysis and global sensitivity analysis [31]. There are many sensitivity analysis methods, such as trajectory sensitivity analysis (TSA), output sensitivity analysis, matrix sensitivity analysis, comparative sensitivity analysis and characteristic root sensitivity analysis [32-33]. When the relationship between input and output is complicated, the application of Kriging model, Monte Carlo method and orthogonal experiment method can determine the implicit function relationship between input and output and improve calculation accuracy [34].

The modal characteristics directly affect the performance of the fluid transmission system, but the free vibration analysis of the hydraulic opposing cylinder controlled by servo valve has not been carried out yet. Therefore, based on the consideration of the equivalent stiffness of oil and the mechanical-hydraulic coupling characteristics [33-34], this paper establishes the free vibration dynamics model and equations of the hydraulic opposing cylinder controlled by servo valve to determine the system modal characteristic and uses the finite difference method to analyze the influence law of the main parameters of the system on the natural frequency and the sensitivity change law of the natural frequency on each main parameter, whose correctness is verified by modal experiments.

\section{System dynamics model and equation}

The composition of the hydraulic opposing cylinder controlled by servo valve is shown in Figure 1. The left cylinder is a loading hydraulic cylinder with displacement sensors and force sensors while the right cylinder is a steering gear hydraulic cylinder with displacement sensors. When working, the two sets of hydraulic cylinders clamp the test piece and move according to their own control laws. The electro-hydraulic simulator adopts a dynamic loading method which means the loading hydraulic cylinder is force closed-loop control, and the steering gear hydraulic cylinder is position closed-loop control. The loading cylinder apply load to the steering gear cylinder, and the steering gear cylinder which moves according to the set law. 


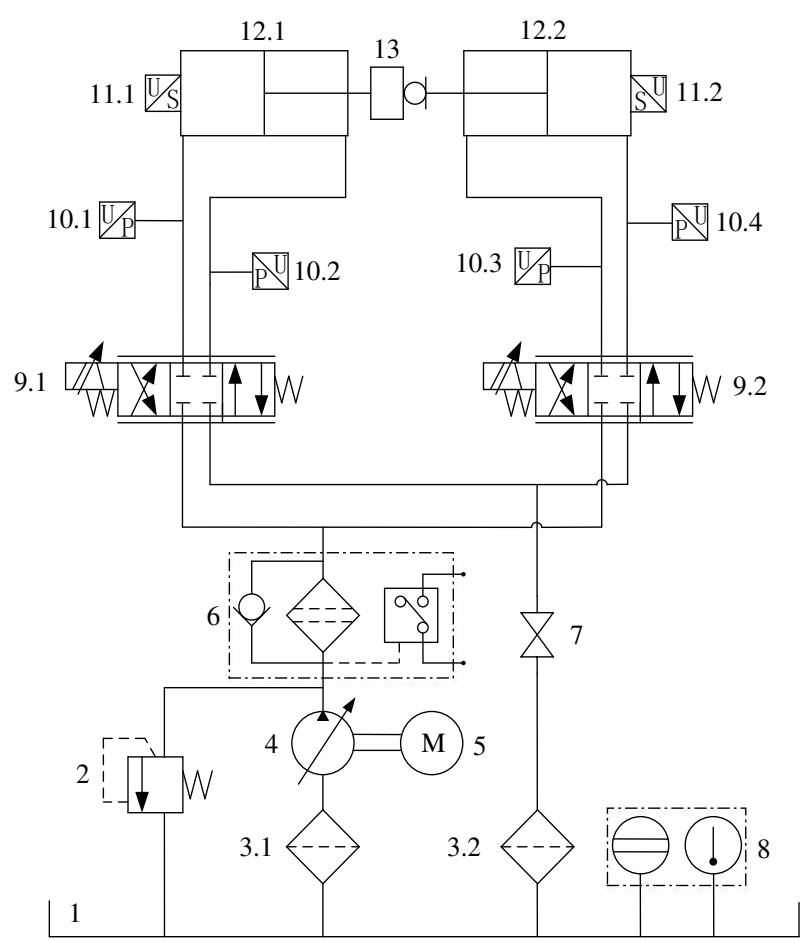

1. Oil tank 2 Overflow valve 3 Filter 4 Plunger pump 5 Motor 6

Fine filter 7 Ball valve 8 Liquid temperature gauge 9

Electro-hydraulic servo valve 10 Pressure sensor 11

Displacement sensor 12 Hydraulic cylinder 13 Force

sensor

Figure 1 The hydraulic system chart of opposing hydraulic cylinder controlled by servo valve

During the working process of this system, due to the pressure pulsation of the pump source, the oil output by the system has harmonic pulsation and the working positions of the hydraulic components such as the hydraulic valve core rod and the piston rod of the hydraulic cylinder constantly changing, resulting in the pressure of hydraulic oil at any position will dynamically change with the adjustment of the chamber and the flow area. Meanwhile, the changing condition of oil will act on different positions of the component in the form of load or internal excitation and affect the position and speed of the component. Therefore, the movement or deformation of the hydraulic components will affect the motion state of oil and changes in the state parameters such as flow and pressure will also cause the hydraulic components to move or deform.

The interaction between the units in the hydraulic system chart of opposing hydraulic cylinder controlled by servo valve is shown in Figure 2. It can be seen that there is an interaction between the two chambers of the loading cylinder and the steering gear cylinder and the piston, which makes the system have mechanical-hydraulic coupling dynamics and its dynamic analysis more complex.

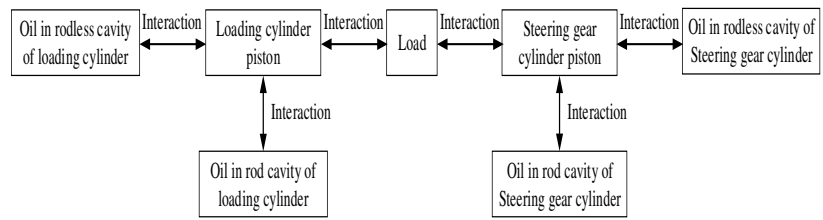

Figure 2 The interaction between the units in the system of opposing hydraulic cylinder controlled by servo valve

In order to simplify the difficulties encountered in modeling and calculation, the following assumptions are given:

(1) The model is established by using the lumped parameter method. It is considered that the density, stiffness, pressure and other attribute parameters of each fluid unit in the system are uniformly distributed in the control volume and equal everywhere;

(2) The hydraulic cylinder shell is regarded as a rigid body and its elastic deformation is ignored;

(3) The force acting on the oil and the piston is the axial force, and only the axial vibration of the system is considered;

(4) The processing and assembly errors of the components of the system are ignored.

The free vibration dynamic model of the system of opposing hydraulic cylinder controlled by servo valve is shown in Figure 3. In the figure, $m_{1}$ is the equivalent mass of the moving part of the loading cylinder, including the mass of oil in the loading cylinder chambers, piston mass, piston rod mass and force sensor mass. $m_{2}$ is the load mass. $m_{3}$ is the equivalent mass of the steering gear cylinder moving part, including the mass of oil in the steering gear hydraulic cylinder chambers, the piston mass and the piston rod mass. $k_{\mathrm{f} 1}$ and $k_{\mathrm{f} 2}$ are the equivalent stiffness of the rodless chamber and the rod chamber of the loading cylinder. $k_{\mathrm{f} 3}$ and $k_{\mathrm{f} 4}$ are the equivalent stiffness of the rod chamber and the rodless chamber of the steering gear cylinder. $k_{1}$ and $k_{2}$ are the connection stiffness between the cylinder piston rod and the load and they are equal. $x_{1}, x_{2}, x_{3}$ are the axial displacements of the loading cylinder, the load and the steering gear cylinder.

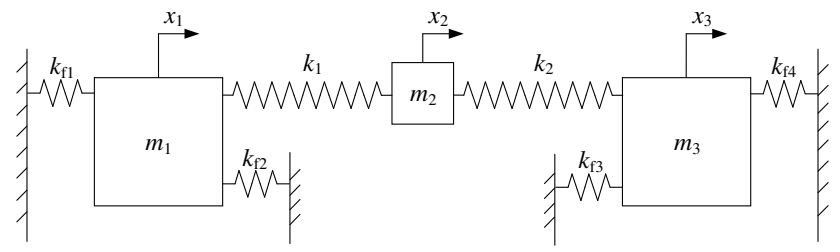


Figure 3 The free vibration dynamic model of the system of opposing hydraulic cylinder controlled by servo valve

Based on the free vibration dynamics model of the system, the system dynamics equation can be established as

\section{$M x=0$}

The quality matrix of the system is

$$
\boldsymbol{M}=\left[\begin{array}{lll}
m_{1} & & \\
& m_{2} & \\
& & m_{3}
\end{array}\right]
$$

The stiffness matrix is

$$
\boldsymbol{K}=\left[\begin{array}{ccc}
k_{\mathrm{f} 1}+k_{\mathrm{f} 2}+k_{1} & -k_{1} & 0 \\
-k_{1} & k_{1}+k_{2} & -k_{2} \\
0 & -k_{2} & k_{2}+k_{\mathrm{f} 3}+k_{\mathrm{f} 4}
\end{array}\right]
$$

In order to solve the free vibration response of the system, the dynamic equivalent stiffness of oil needs to be calculated. During the working process of the system, the way of oil compression is similar to that of spring, so the dynamic equivalent stiffness of oil can be expressed by the following formula, where $\mathrm{i}=1,2,3,4$.

$$
k_{\mathrm{f} i}=-\frac{\Delta F}{\Delta L_{i}}
$$

Where $k_{\mathrm{fi}}$ is the dynamic equivalent stiffness of oil in each chamber $(\mathrm{N} \cdot \mathrm{m}), \Delta F$ is the variation of the exogenic force acting on the system $(\mathrm{N}), \Delta L_{i}$ is the variation of the axial length of oil in each chamber $(\mathrm{m})$.

The oil volume of each chamber is

$$
V_{i}=S_{\mathrm{Aj}} L_{i}
$$

Where $V_{i}$ is the volume of oil in each chamber(m3), $S_{\mathrm{A} j}$ is the cross-sectional area of oil in each chamber $(\mathrm{m} 2), S_{\mathrm{A} 1}$ is the cross-sectional area of oil in the rodless chamber, $S_{\mathrm{A} 2}$ is the cross-sectional area of oil in the rod chamber, $L_{i}$ is the axial length of oil in each chamber.

According to the theory of bulk modulus, assuming that $E$ is bulk modulus of oil, then its definition can be expression as

$$
E=-V \frac{\mathrm{d} p}{\mathrm{~d} V}
$$

Where $p$ is the pressure of oil (MPa)

Simultaneous Eq. (4), Eq. (5) and Eq. (6), the dynamic equivalent stiffness of oil is

$$
k_{\mathrm{f} i}=\frac{E_{\mathrm{f} i} S_{\mathrm{A} j}}{L_{i}}
$$

Where $E_{\mathrm{f} i}$ is the dynamic bulk modulus of oil in each chamber (MPa).

In the actual working condition, the pressure pulsation of the pump source is inevitable. The pressure pulsation of oil in each chamber will cause the density of oil to fluctuate, resulting in the fluctuation of the dynamic bulk modulus of oil, and ultimately affect the dynamic equivalence stiffness of oil. Therefore, assuming that the pulsating pressure changes according to the law of cosine, and is divided into steady part and dynamic part, the pressure pulsation of oil can be written as follows

$$
p_{i}=p_{i 0}+\Delta p_{i} \cos \left(2 \pi f_{0} t\right)
$$

Where $p_{i 0}$ is the stable value of the pressure in each chamber(MPa), $\Delta p_{i}$ is the impulse value of the pressure in each chamber(MPa), $f_{0}$ is the pulsation frequency of pressure $(\mathrm{Hz})$.

\section{System modal analysis}

The design parameters of the modal analysis of the opposing hydraulic cylinder controlled by servo valve are shown in Table 1.

Table 1 Design parameters of the system

\begin{tabular}{llll}
\hline Parameter name & $\begin{array}{l}\text { Parameter } \\
\text { symbol }\end{array}$ & $\begin{array}{l}\text { Parameter } \\
\text { Unit }\end{array}$ & $\begin{array}{l}\text { Parameter } \\
\text { value }\end{array}$ \\
\hline $\begin{array}{l}\text { Stable value of rodless chamber } \\
\text { pressure of the loading cylinder }\end{array}$ & $p_{10}$ & $\mathrm{MPa}$ & 1.09 \\
$\begin{array}{l}\text { Impluse value of rodless chamber } \\
\text { pressure of the loading cylinder }\end{array}$ & $\Delta p_{1}$ & $\mathrm{MPa}$ & 0.04 \\
$\begin{array}{l}\text { Stable value of rod chamber } \\
\text { pressure of the loading cylinder }\end{array}$ & $p_{20}$ & $\mathrm{MPa}$ & 1.657 \\
$\begin{array}{l}\text { Impluse value of rod chamber } \\
\text { pressure of the loading cylinder }\end{array}$ & $\Delta p_{2}$ & $\mathrm{MPa}$ & 0.032 \\
$\begin{array}{l}\text { Stable value of rod chamber } \\
\text { pressure of the steering gear cylinder }\end{array}$ & $p_{30}$ & $\mathrm{MPa}$ & 1.059 \\
$\begin{array}{l}\text { Impluse value of rod chamber } \\
\text { pressure of the steering gear cylinder }\end{array}$ & $\Delta p_{3}$ & $\mathrm{MPa}$ & 0.054 \\
$\begin{array}{l}\text { Stable value of rodless chamber } \\
p_{40}\end{array}$ & $\mathrm{MPa}$ & 1.605 \\
\hline
\end{tabular}


pressure of the steering gear cylinder Impluse value of rodless chamber pressure of the steering gear cylinder $\Delta p_{4} \quad \mathrm{MPa} \quad 0.022$

Stable value of dynamic stiffness of oil in the rodless chamber of the $k$ loading cylinder

Stable value of dynamic stiffness of oil in the rod chamber of the loading $k_{\mathrm{f} 2} \quad \mathrm{~N} / \mathrm{m} \quad 2.006 \times 10^{7}$ cylinder

Stable value of dynamic stiffness of oil in the rod chamber of the steering $k_{\mathrm{f}}$ gear cylinder

Stable value of dynamic stiffness of oil in the rodless chamber of the $k_{\mathrm{f} 4}$ steering gear cylinder

Temperature

$$
T
$$$$
\mathrm{N} / \mathrm{m} \quad 1.471 \times 10^{7}
$$$$
\mathrm{N} / \mathrm{m} \quad 1.64 \times 10^{7}
$$$$
\mathrm{N} / \mathrm{m} \quad 1.66 \times 10^{7}
$$$$
{ }^{\circ} \mathrm{C} \quad 44.3
$$

Based on the design parameters in Table 1, the dynamic natural frequencies of each order of the system of opposing hydraulic cylinder controlled by servo valve within 5 seconds are obtained, as shown in Figure 4.

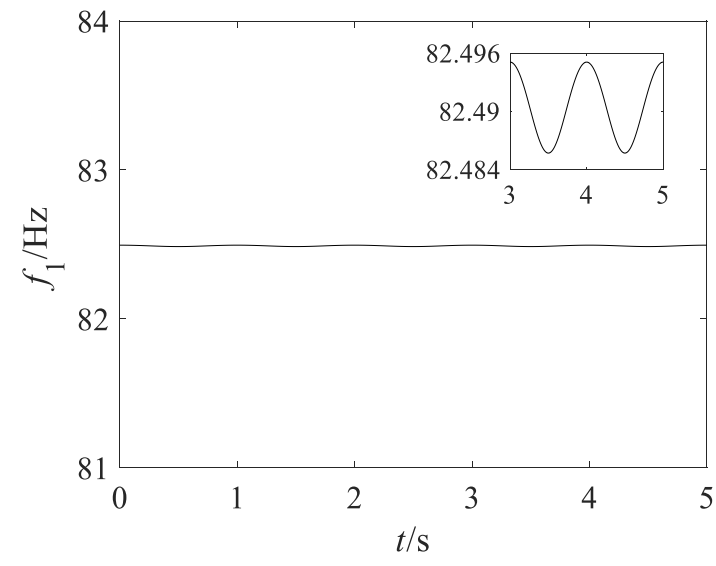

(a) First-order dynamic natural frequency

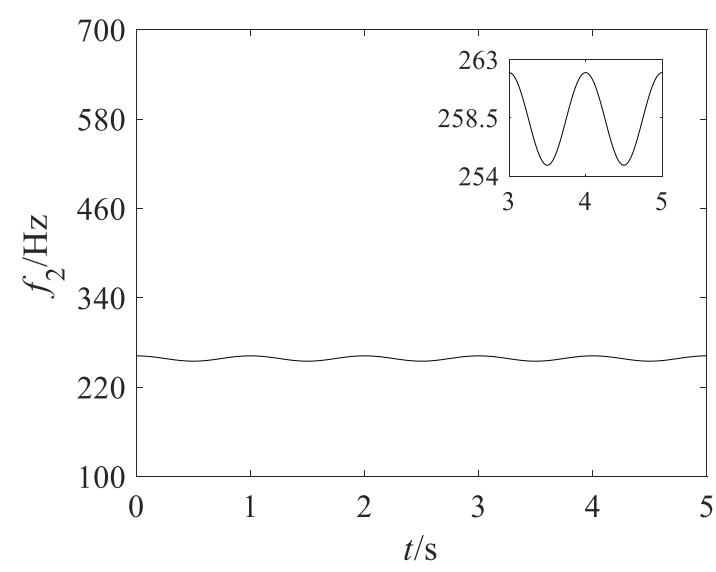

(b) Second-order dynamic natural frequency

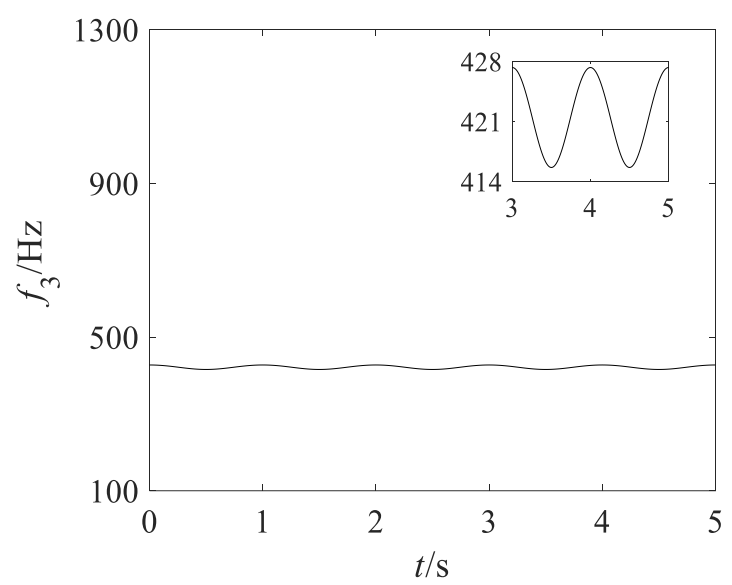

(c) Third-order dynamic natural frequency.

Figure 4 Variation with time of each order natural frequency of opposing hydraulic cylinder system controlled by servo valve

It can be seen from Figure 4 that within the calculation time, the dynamic natural frequency of each order of the system is relatively stable and only small fluctuations occur. Among them, the average value of the first-order dynamic natural frequency fluctuation is $82.49 \mathrm{~Hz}$, the ones of the second and third-order are $258.5 \mathrm{~Hz}$ and $421.6 \mathrm{~Hz}$. From the perspective of the degree of fluctuation, the first-order dynamic natural frequency has the smallest fluctuation and the third-order one has the largest one.

Table 2 and Table 3 respectively show the natural frequencies and main vibration modes of the system at different times.

Table 2 Dynamic natural frequencies of each order and its main vibration mode at $1.25 \mathrm{~s}$

\begin{tabular}{|c|c|c|c|}
\hline Order number & First-order & Second-order & Third-order \\
\hline $\begin{array}{ll}\text { Natural frequency } \\
f_{i} / \mathrm{Hz}\end{array}$ & 82.49 & 258.51 & 421.70 \\
\hline vibration & 0.0038 & 1 & $4.1323 \times 10^{-5}$ \\
\hline \multirow{2}{*}{$\begin{array}{l}\text { mode of each order } \\
\boldsymbol{\Phi}_{i}\end{array}$} & 1 & -0.0569 & -0.02 \\
\hline & 0.0038 & $-3.3024 \times 10^{-4}$ & 1 \\
\hline
\end{tabular}

Table 3 Dynamic natural frequencies of each order and its main vibration mode at $5 \mathrm{~s}$

\begin{tabular}{|c|c|c|c|}
\hline Order number & First-order & Second-order & Third-order \\
\hline $\begin{array}{ll}\text { Natural frequency } \\
f_{i} / \mathrm{Hz}\end{array}$ & 82.49 & 261.99 & 421.32 \\
\hline $\begin{array}{l}\text { Main vibration } \\
\text { mode of each order }\end{array}$ & 0.0037 & 1 & $3.9157 \times 10^{-5}$ \\
\hline 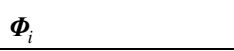 & 1 & -0.0552 & -0.0194 \\
\hline
\end{tabular}


$0.0037 \quad-3.1224 \times 10^{-4} \quad 1$

It can be seen from Table 2 and Table 3 that in the calculation time, the dynamic natural frequencies of each order of the system of opposing hydraulic cylinder controlled by servo valve and its main vibration mode are relatively stable with small changes. From the perspective of the main vibration, it can be seen that whether the system vibration frequency is the first, second or third-order natural frequencies, the order of the largest vibration displacement is all load, loading cylinder and steering gear cylinder. When the system vibration frequency is the second-order natural frequency, the displacement of the load and the steering gear cylinder are very small and the loading cylinder has the maximum displacement. When the system's vibration frequency is the third-order natural frequency, its vibration law is similar to that at the second-order natural frequency. When the vibration frequency of the system is the first-order natural frequency, the load displacement reaches the maximum, the displacement of the loading cylinder and the steering gear cylinder are equal with small value, showing a "symmetrical" phenomenon, which conforms to the structural characteristics of the system of opposing hydraulic cylinder controlled by servo valve. Under normal circumstances, the external excitation frequency is most likely to be close to the first-order natural frequency of the system, which means the load is most likely to vibrate. For the electro-hydraulic simulator, when the load vibrates severely, the tracking accuracy of the system will decrease and have an impact on the control performance of the system.

\section{Sensitivity analysis of system natural frequency}

The load mass, the equivalent mass of the movement part of the loading cylinder, the equivalent mass of the movement part of the steering gear cylinder, the connection stiffness and the equivalent stiffness of oil are the main factors which affect the natural frequency of the system of opposing hydraulic cylinder controlled by servo valve. In order to analyze the influence of these factors on the natural frequency of the system, in this section, based on the control variable method, the sensitivity of the natural frequency of the system to the above factors is discussed.

\subsection{Sensitivity analysis of system natural frequency to load frequency}

When the load mass varies from $0.7 \mathrm{~kg}$ to $1.1 \mathrm{~kg}$ and the rest of the system parameters remain unchanged, the changes in the natural frequencies of each order of the system and their sensitivity to the load mass are shown in Figure 5. Among them, $S_{1}, S_{2}, S_{3}$ are the first, second and third-order dynamic natural frequency sensitivity.

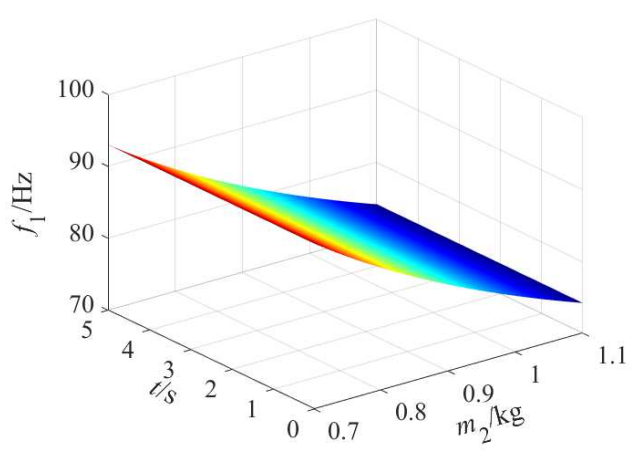

(a) First-order dynamic natural frequency

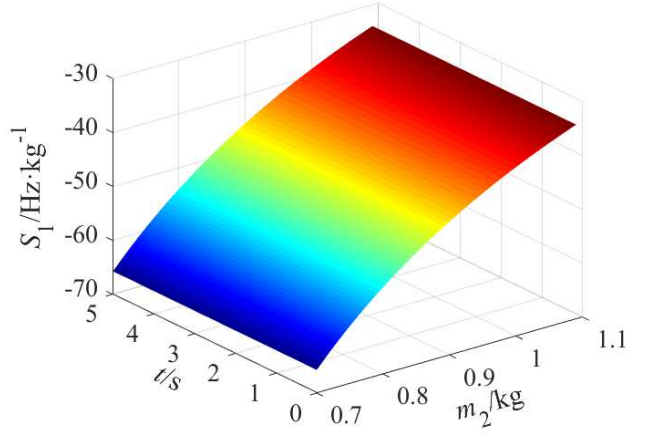

(b) First-order dynamic natural frequency sensitivity

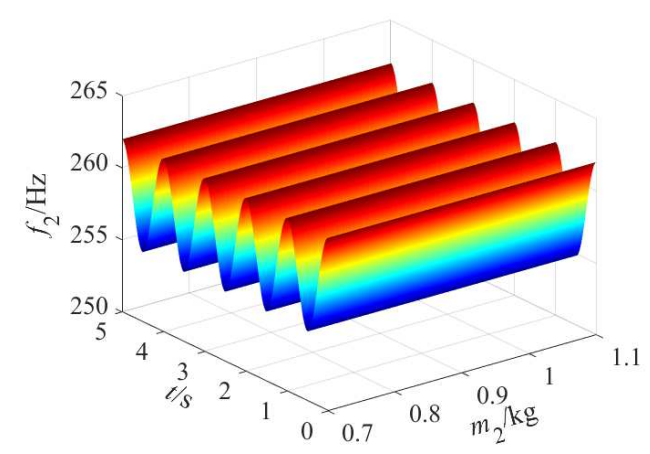

(c) Second-order dynamic natural frequency 


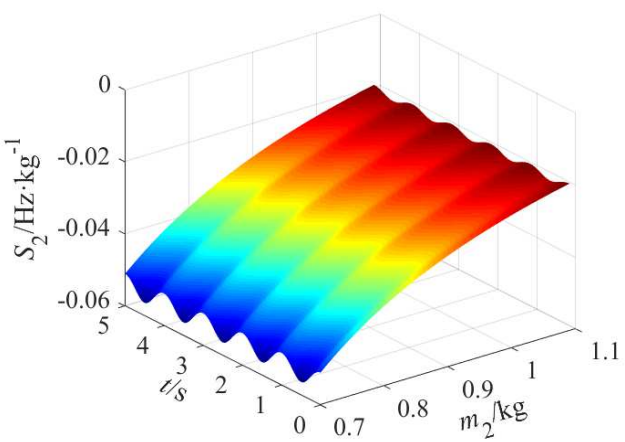

(d) Second-order dynamic natural frequency sensitivity

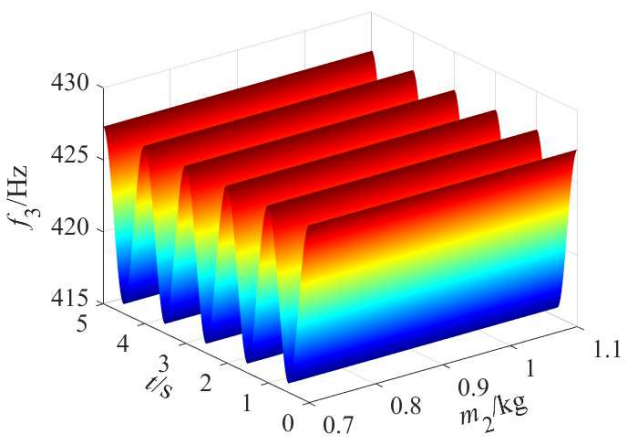

(e) Third-order dynamic natural frequency

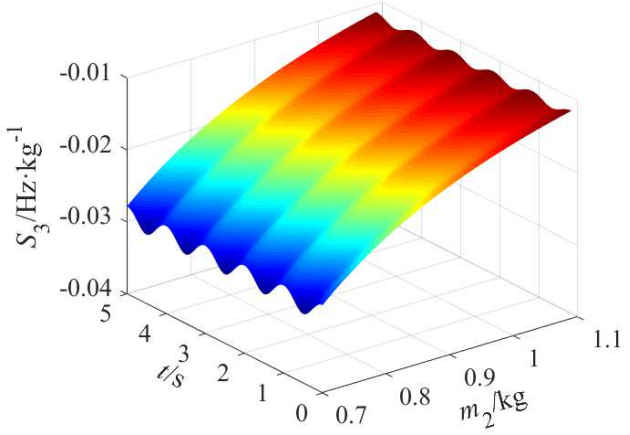

(f) Third-order dynamic natural frequency sensitivity

Figure 5 The natural frequency of each order of the system and its sensitivity to load mass

Figure 5 (a) and (b) shows that at the same time, as the load mass increases, the first-order dynamic natural frequency of the system decreases significantly and the sensitivity of the first-order dynamic natural frequency to the load quality is negative value. In addition, the first-order dynamic natural frequency sensitivity $S_{1}$ gradually decreases as the load mass increases, which is reflected in the figure (a) that when the load mass gradually increases, the rate of decrease of the first-order dynamic natural frequency slows down.

Figure 5 (c) to (f) are the second and third-order dynamic natural frequencies of the system and their sensitivity changes to the load quality. The change law is basically the same as that of the first-order dynamic natural frequency. The difference is that from numerical aspect, both the second and third-order dynamic natural frequencies and their sensitivity have small changes. Therefore, by comparing the sensitivity curves in Figure 5, it can be seen that the first-order dynamic natural frequency is the most sensitive to changes in load quality while the second and third-order dynamic natural frequencies are less sensitive.

\subsection{Sensitivity analysis of system natural frequency to equivalent mass of the moving part of the loading cylinder}

When the load mass varies from $12 \mathrm{~kg}$ to $15 \mathrm{~kg}$ and the rest of the system parameters remain unchanged, the changes in the natural frequencies of each order of the system and their sensitivity changes to the equivalent mass of the moving part of the loading cylinder are shown in Figure 6.

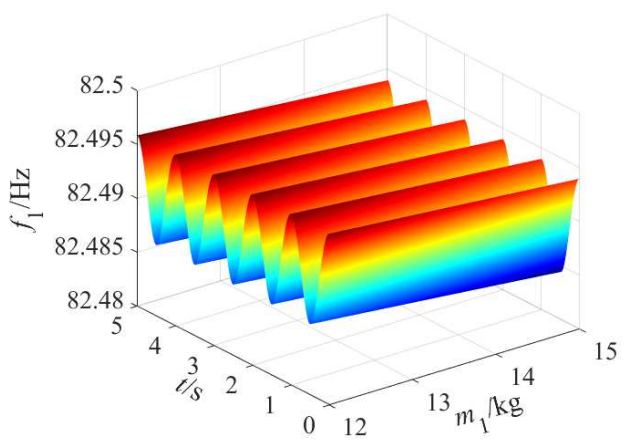

(a) First-order dynamic natural frequency

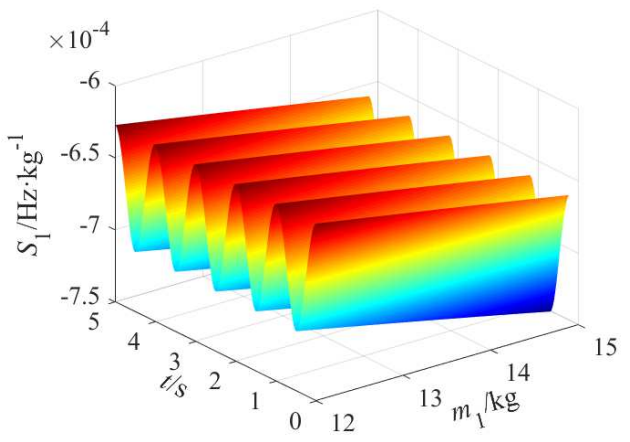

(b) First-order dynamic natural frequency sensitivity 


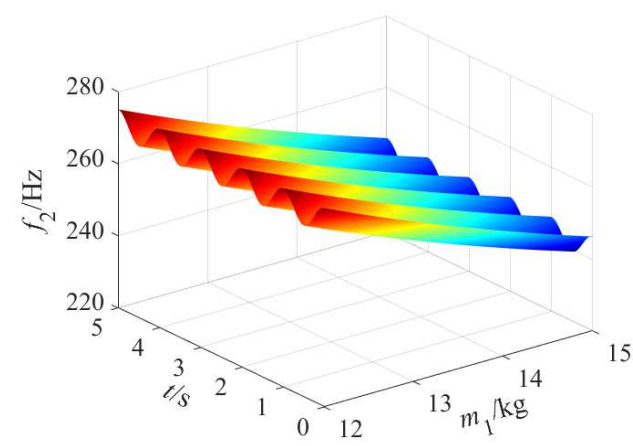

(c) Second-order dynamic natural frequency

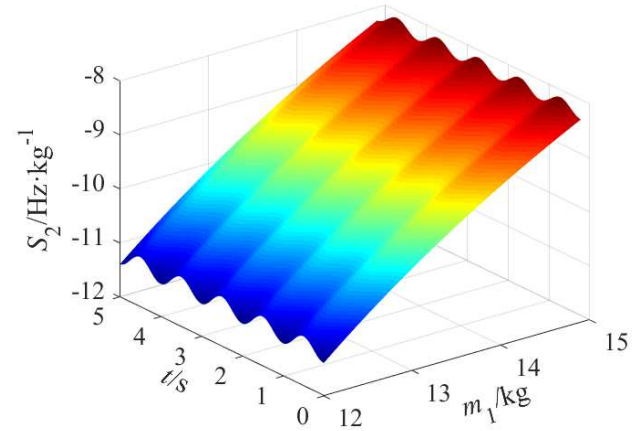

(d) Second-order dynamic natural frequency sensitivity

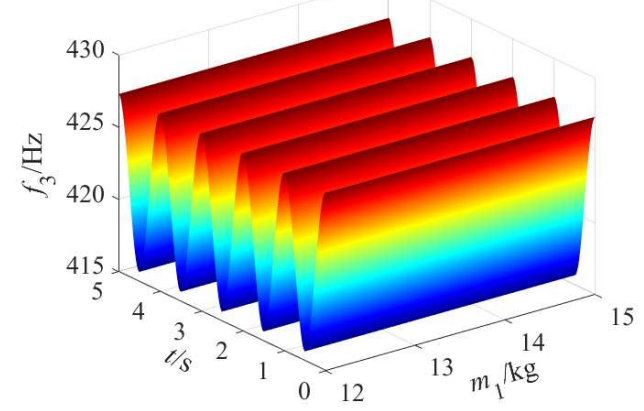

(e) Third-order dynamic natural frequency

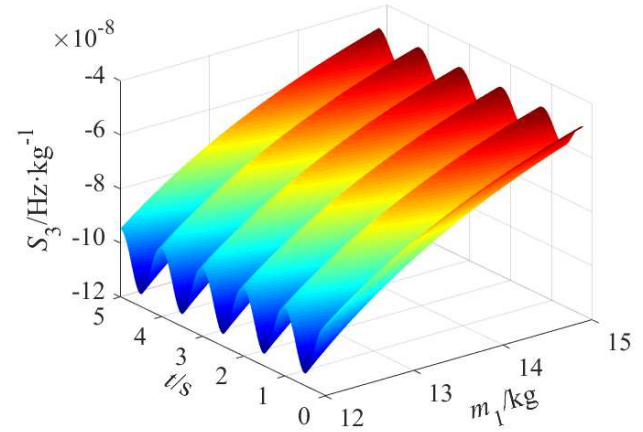

(f) Third-order dynamic natural frequency sensitivity

Figure 6 The natural frequency of each order of the system and its sensitivity to equivalent mass of the moving part of the loading cylinder
It can be seen from Figure 6 (a) and (b) that at the same time, as the equivalent mass $m_{1}$ of the moving part of the loading cylinder increases, the first-order dynamic natural frequency of the system decreases slightly and the decreasing rate has a tendency to accelerate. The sensitivity $S_{1}$ is negative in value and its absolute value gradually increases with the increase of $m_{1}$. In Figure 6 (c) to (f), the second and third-order dynamic natural frequencies and their sensitivity changes are similar. The difference is that the second-order dynamic natural frequency decreases more with the increase of $m_{1}$ and its sensitivity $S_{2}$ has a significant increase. By comparing the sensitivity curves in Figure 6, it can be seen that the second-order dynamic natural frequency is the most sensitive to the change of the equivalent mass of the moving part of the loading cylinder while the third-order dynamic natural frequency is the least sensitive.

\subsection{Sensitivity analysis of system natural frequency to equivalent mass of the moving part of the steering gear cylinder}

When the equivalent mass of the motion part of the steering gear cylinder varies from $4 \mathrm{~kg}$ to $6 \mathrm{~kg}$ and the rest of the system parameters of the remain unchanged, the natural frequencies of each order of the system and the sensitivity changes to the equivalent mass of the motion part of the steering gear cylinder are shown in Figure 7.

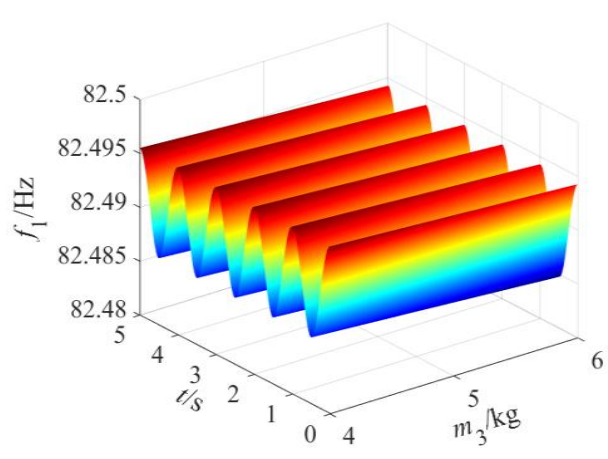

(a) First-order dynamic natural frequency

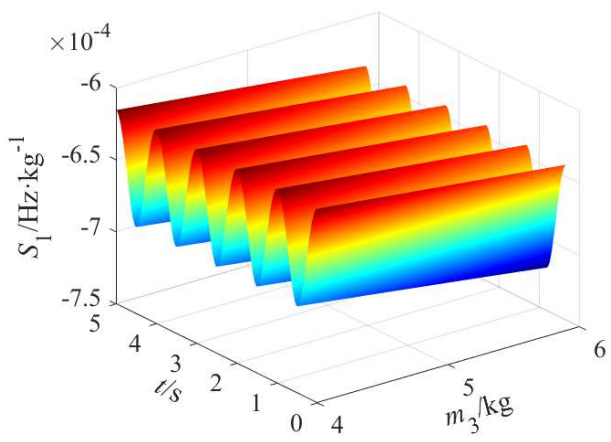


(b) First-order dynamic natural frequency sensitivity

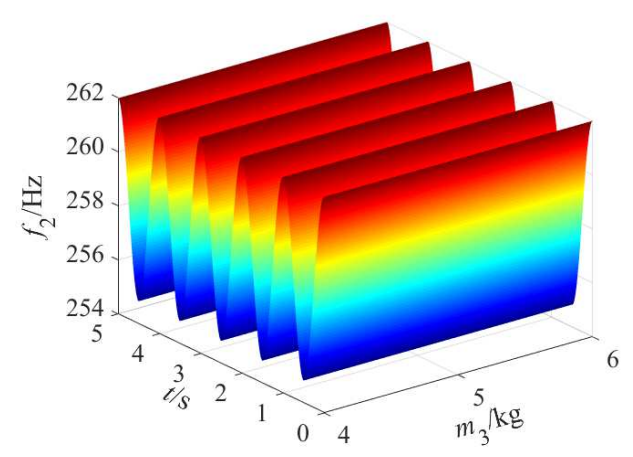

(c) Second-order dynamic natural frequency

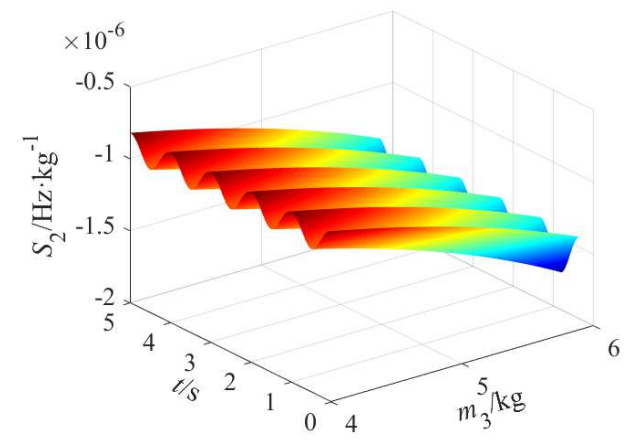

(d) Second-order dynamic natural frequency sensitivity

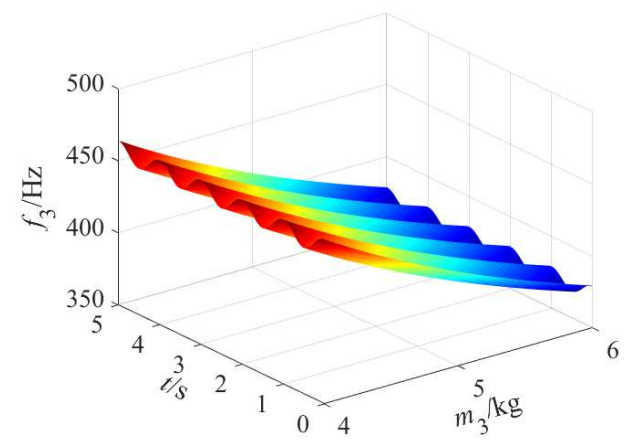

(e) Third-order dynamic natural frequency

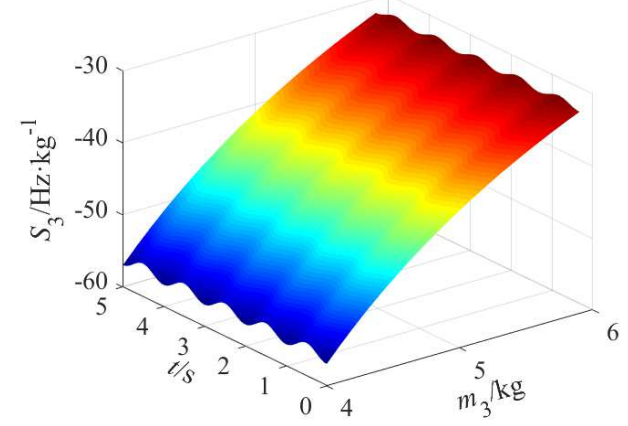

(f) Third-order dynamic natural frequency sensitivity

Figure 7 The natural frequency of each order of the system and its sensitivity to the equivalent mass of the moving part of the steering gear cylinder
It can be seen from Figure 7 (a) to (d) that the first and second order dynamic natural frequencies and their sensitivity changes are similar. At the same time, as the equivalent mass $m_{3}$ of the steering gear cylinder increases, the dynamics natural frequency of the system decreases slightly, and the decreasing rate has a tendency to accelerate. The sensitivity is all negative in value and its absolute value gradually increases with the increase of $m_{3}$. In Figure 7 (e) and (f), the third-order dynamic natural frequency decreases greatly with the increase of $m_{3}$ and its sensitivity $S_{3}$ also has a significant increase. By comparing the sensitivity curves in Figure 7, it can be seen that when the equivalent mass of the movement part of the steering gear increases, the third order dynamic natural frequency changes greatly, so we can draw a conclusion that the third order dynamic natural frequency is the most sensitive to the equivalent mass change of the steering gear cylinder movement while the second-order dynamic natural frequency is the least sensitive.

\subsection{Sensitivity analysis of system natural frequency to connection stiffness of the loading cylinder}

When the connection stiffness of the loading cylinder varies from $1.1 \times 10^{5} \mathrm{~N} / \mathrm{m}$ to $1.3 \times 10^{5} \mathrm{~N} / \mathrm{m}$ and the rest of the system parameters of the remain unchanged, the natural frequencies of each order of the system and the sensitivity changes to the connection stiffness of the loading cylinder are shown in Figure 8.

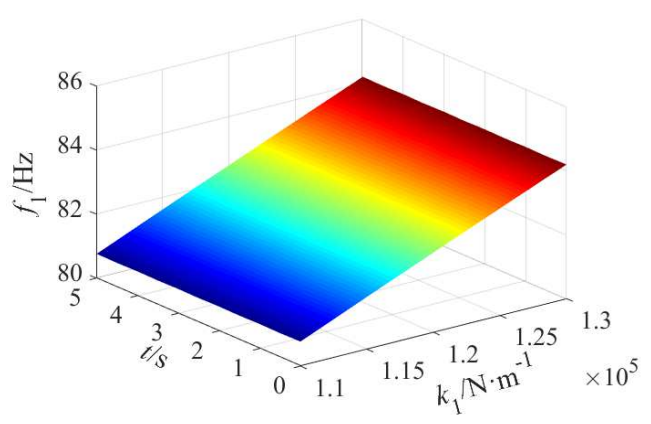

(a) First-order dynamic natural frequency 


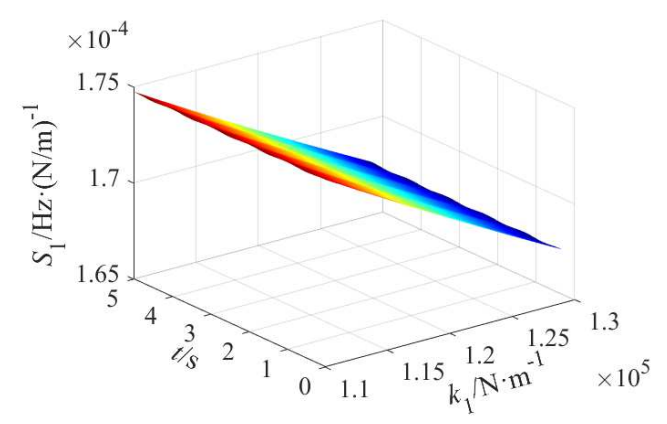

(b) First-order dynamic natural frequency sensitivity

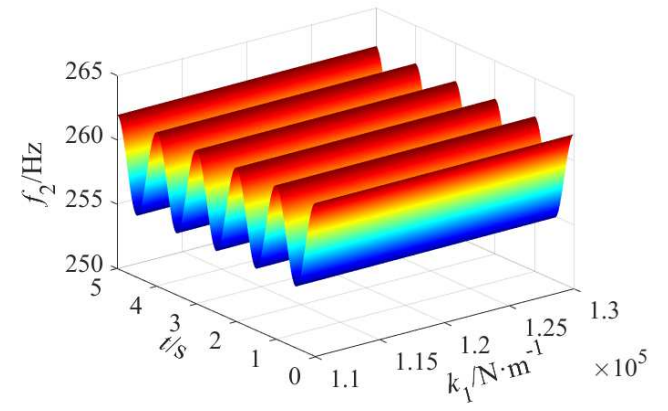

(c) Second-order dynamic natural frequency

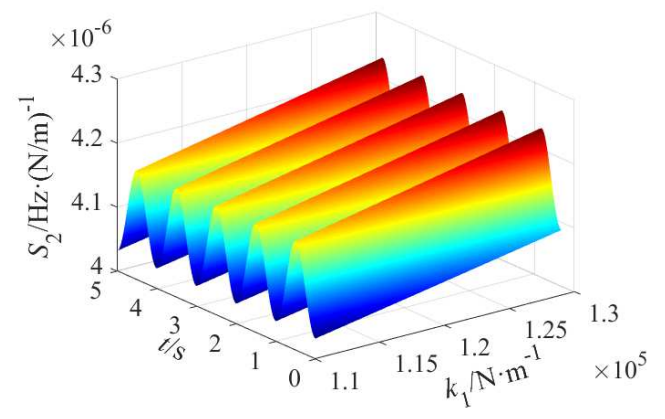

(d) Second-order dynamic natural frequency sensitivity

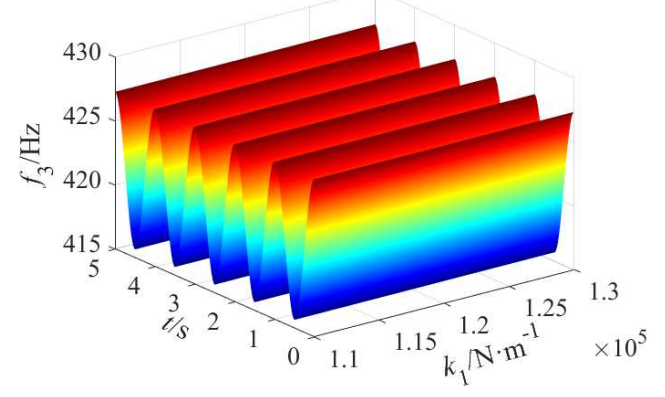

(e) Third-order dynamic natural frequency

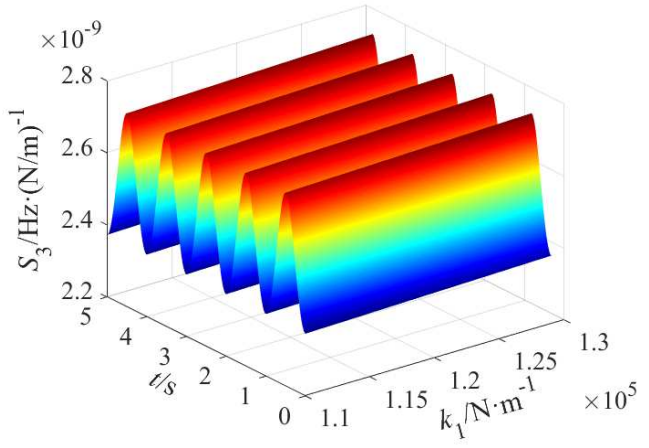

(f) Third-order dynamic natural frequency sensitivity

Figure 8 The natural frequency of each order of the system and its sensitivity to the connection stiffness of the loading cylinder

It can be seen from Figure 8 (a) and (b) that at the same point in time, the first-order dynamic natural frequency increases with the increase of the connection stiffness of the loading cylinder and its sensitivity to the connection stiffness of the loading cylinder are all positive values. Since the sensitivity $S_{1}$ decreases slightly with the increase of the connection stiffness of the loading cylinder, the increase rate of the first-order dynamic natural frequency tends to slow down. In Figure 8 (c) to (f), the second and third-order dynamic natural frequencies and their sensitivity changes are similar. The values of sensitivities $S_{2}$ and $S_{3}$ are so small to draw a conclusion that there are no significant changes of the second and third-order dynamic natural frequencies at the same time. Under the same stiffness, the second and third-order dynamic natural frequencies of the system exhibit a fluctuating state with time, which is consistent with the results in the modal analysis. By comparing the sensitivity curves in Figure 8, it can be seen that when the connection stiffness of the loading cylinder gradually increases, the first-order dynamic natural frequency has the most obvious changes, so we can draw a conclusion that the first-order dynamic natural frequency is the most sensitive to the change of the connection stiffness of the loading cylinder while the third-order dynamic natural frequency is the least sensitive.

\subsection{Sensitivity analysis of system natural frequency to connection stiffness of the loading cylinder}

4.5.1 The equivalent stiffness of oil in the steering gear cylinder oil remains stable

In the working process of the system, the piston in the hydraulic cylinder is simultaneously acted by the pressure of the two chambers of oil and its principle is equivalent to a parallel spring system. The equivalent stiffness of oil is equal to parallel connection equivalent stiffness of oil in 
both the loading cylinder chambers. When the equivalent stiffness of oil in loading cylinder oil varies from $3.2 \times 10^{7} \mathrm{~N} / \mathrm{m}$ to $3.5 \times 10^{7} \mathrm{~N} / \mathrm{m}$ and the rest of the system parameters of the remain unchanged, the natural frequencies of each order of the system and the sensitivity changes to the equivalent stiffness of oil in loading cylinder are shown in Figure 9.

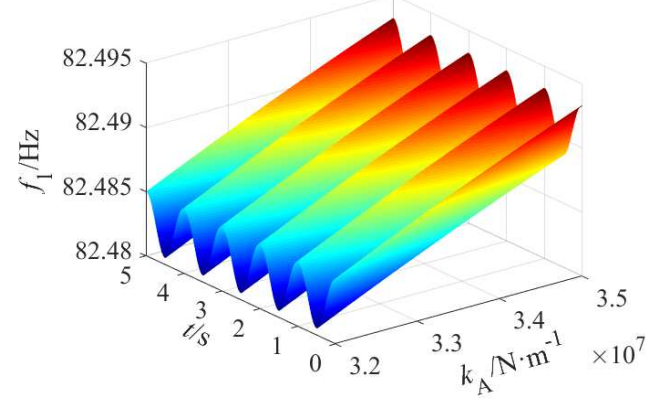

(a) First-order dynamic natural frequency

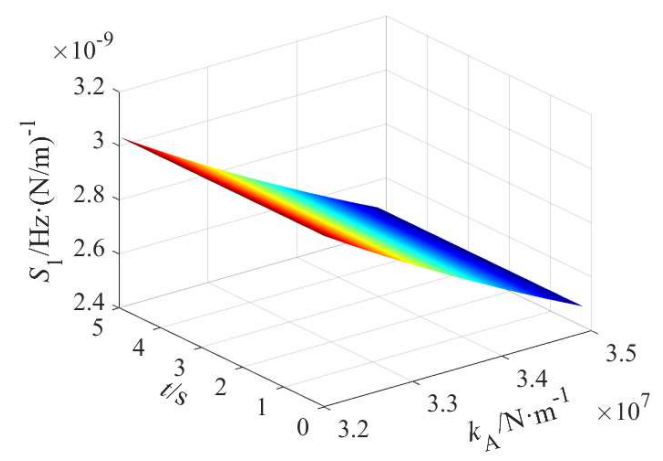

(b) First-order dynamic natural frequency sensitivity

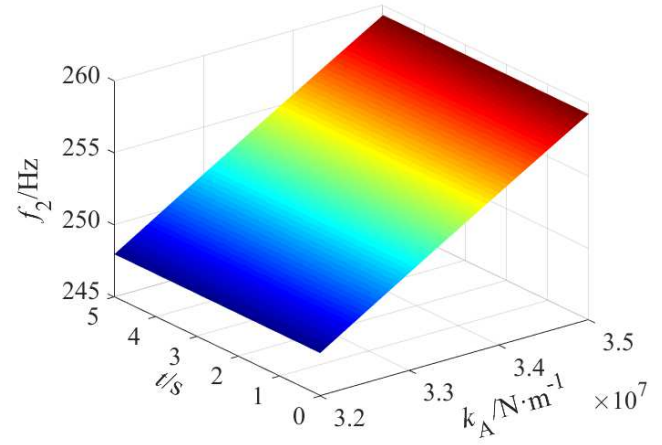

(c) Second-order dynamic natural frequency

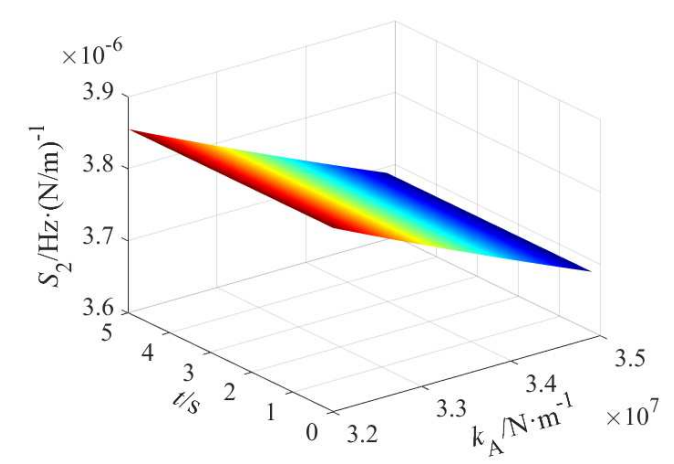

(d) Second-order dynamic natural frequency sensitivity

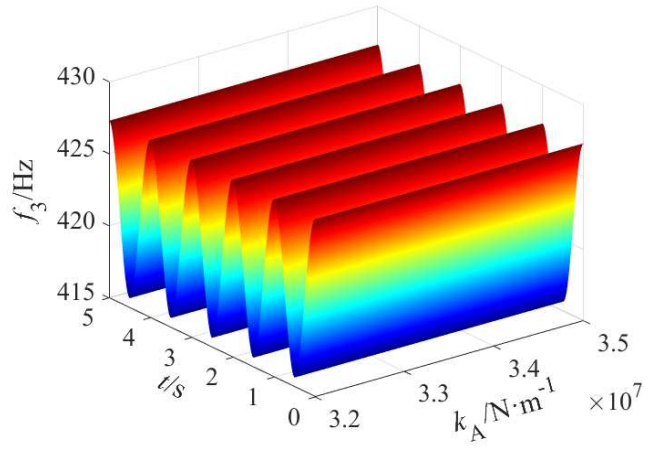

(e) Third-order dynamic natural frequency

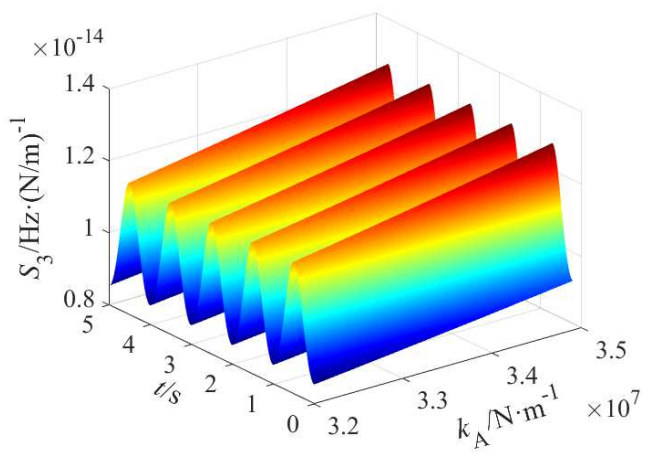

(f) Third-order dynamic natural frequency sensitivity

Figure 9 The natural frequencies of each order of the system and its sensitivity to the oil equivalent stiffness in the loading cylinder

From Figure 9 (a) to (d), it can be seen that the first and second order dynamic natural frequencies of the system and their sensitivity changes are similar. At the same time, when the equivalent stiffness of the loading cylinder oil increases, the dynamic natural frequencies also increase in the rate with the tendency to slow down, which is reflected by the decrease of $S_{1}$ and $S_{2}$. In Figure 9 (e) and (f), since the value of the sensitivity $S_{3}$ is very small, the third-order dynamic natural frequency of the system can be considered basically unchanged at the same time. By comparing the sensitivity curves in Figure 9, it can be seen that the second-order dynamic natural frequency is the most sensitive to changes 
in the equivalent stiffness of oil in the loading cylinder while the third-order is the least sensitive.

\subsubsection{The equivalent stiffness of oil in the steering gear cylinder oil changes}

Utilizing the "symmetrical" characteristic of the system, the equivalent stiffness of the loading cylinder oil and the equivalent stiffness of the steering gear cylinder oil are equal, and both vary from $3.2 \times 10^{7} \mathrm{~N} / \mathrm{m}$ to $3.5 \times 10^{7} \mathrm{~N} / \mathrm{m}$ and he rest of the system parameters of the remain unchanged, the natural frequencies of each order of the system and the sensitivity changes to the equivalent stiffness of oil in loading cylinder are shown in Figure 10.

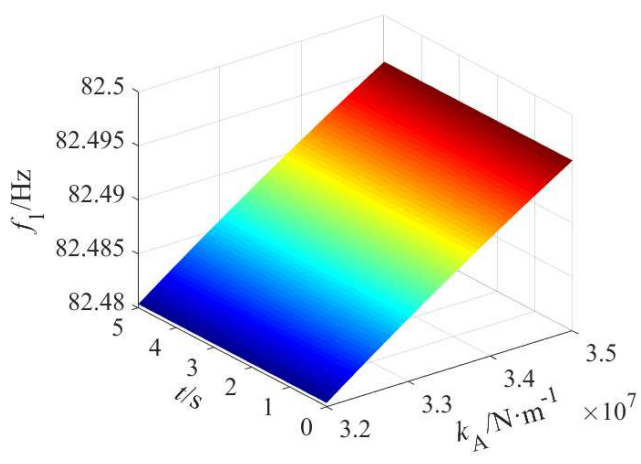

(a) First-order dynamic natural frequency

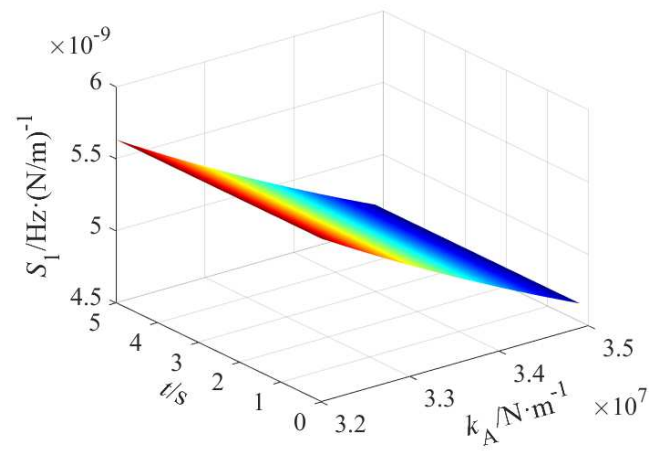

(b) First-order dynamic natural frequency sensitivity

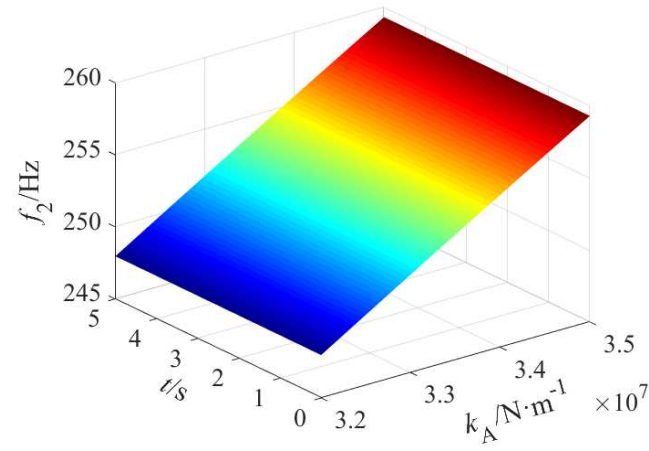

(c) Second-order dynamic natural frequency

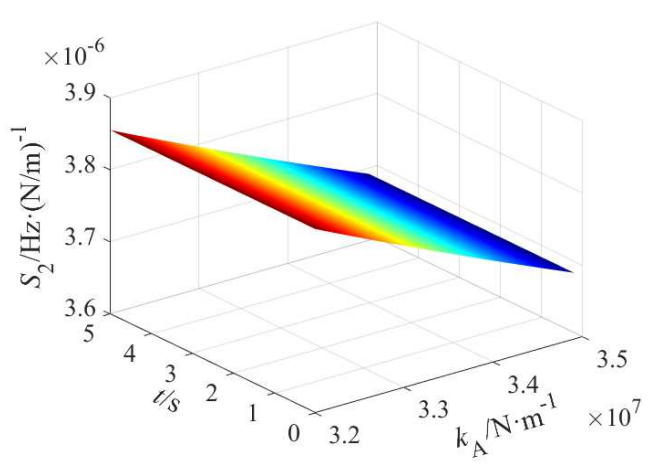

(d) Second-order dynamic natural frequency sensitivity

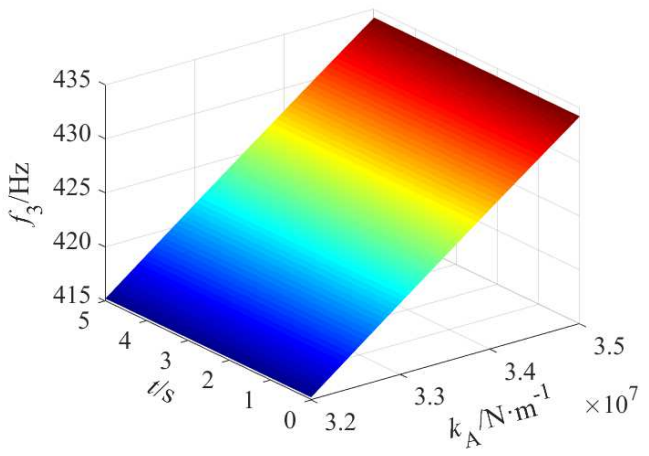

(e) Third-order dynamic natural frequency

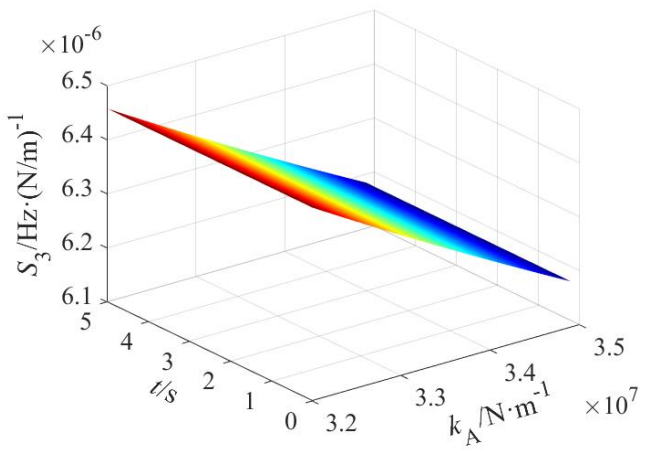

(f) Third-order dynamic natural frequency sensitivity

Figure 10 The natural frequencies of each order of the system and its sensitivity to the oil equivalent stiffness in the loading cylinder when the oil equivalent stiffness in the steering gear cylinder changes

It can be seen from Figure 10 (a) and (b) that at the same time, when the equivalent stiffness of the loading cylinder oil increases, the first-order dynamic natural frequency of the system also increases which can be reflected that the value of $S_{1}$ is positive. Besides, $S_{1}$ decreases with the increase of $k_{\mathrm{A}}$, indicating that the growth rate of the firstorder dynamic natural frequency slows down. In Figure 10 (c) to (f), the second and third-order dynamic natural frequencies of the system and the change law of its sensitivity to the equivalent stiffness of the loading cylinder 
oil are similar to those of the first-order, with only numerical differences. By comparing the sensitivity curves of the natural frequencies in Figure 10, it can be seen that when the equivalent stiffness of the loading cylinder oil is equal to the equivalent stiffness of the steering gear cylinder, the thirdorder dynamic natural frequency is the most sensitive to the equivalent stiffness of oil in loading cylinder while the firstorder dynamic natural frequency is the least sensitive. The schematic diagram of the modal experiment is shown in Figure 11.

\section{Test verification}

In order to verify the accuracy of the system's modal analysis, an experiment platform of the system of opposing hydraulic cylinder controlled by servo valve is built and the modal test of the system in the working process was carried out by using the hammering method. The force hammer strikes, exerts an exciting force whose signal enters the lower computer through the force sensor and voltage amplifier on the force hammer. The acceleration change of the system is collected by the acceleration sensor and input to the computer through the voltage amplifier and the lower computer. The experimental platform is shown in Figure 12, and the experimental parameters are consistent with those shown in Table 1.

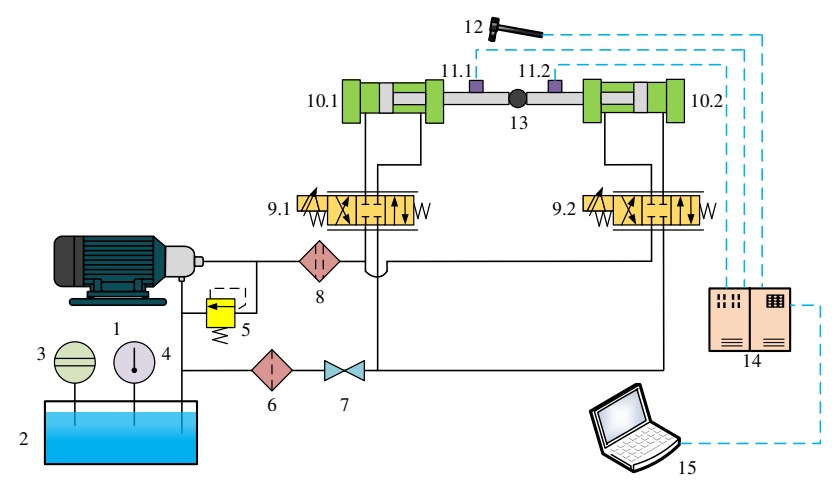

1 Motor pump 2 Oil tank 3 Liquid level gauge 4 Liquid temperature gauge 5 Overflow valve 6 Filter 7 Check valve 8 Fine filter 9 Servo valve 10 Hydraulic cylinder 11 Acceleration sensor 12 Force hammer 13 Load 14 Lower computer 15 Computer

Figure 11 Schematic diagram of modal experiment

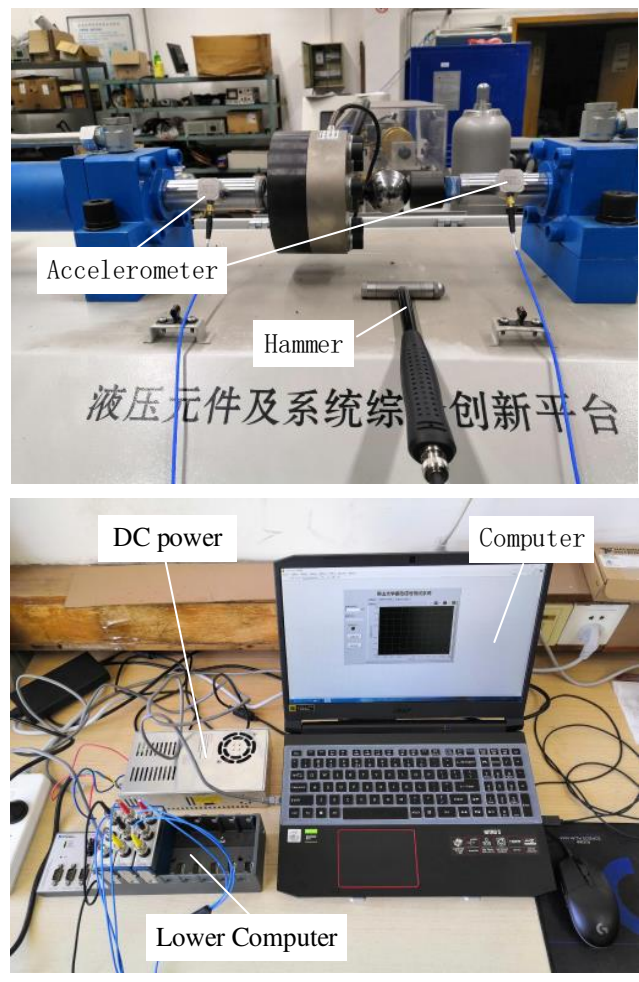

Figure 12 Experiment platform of the system of opposing hydraulic cylinder controlled by servo valve

According to the sampling theorem, in order to ensure the authenticity and accuracy of the signal, the sampling frequency should be 2 to 5 times the maximum value of the modal frequency contained in the signal. In the modal experiment, the sampling frequency is $4096 \mathrm{~Hz}$. Therefore, the experiment can satisfy all the results of the modal frequency below $819.2 \mathrm{~Hz}$. According to the theoretical modal analysis, the maximum frequency of the system is less than $819.2 \mathrm{~Hz}$ so the sampling frequency meets the experimental requirements.

The excitation force signal and acceleration response signal measured in the experiment are shown in Figure 13.

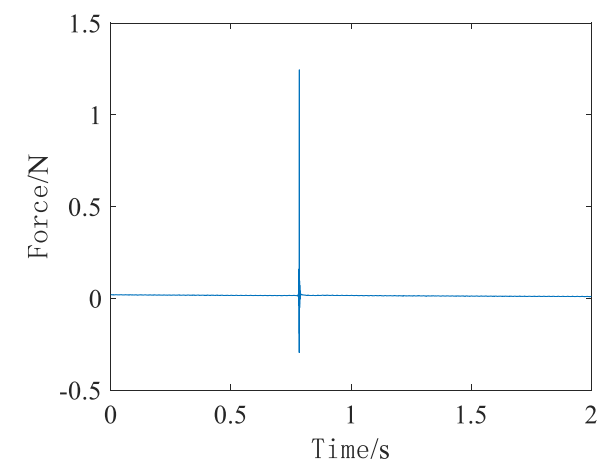

(a) Excitation signal 


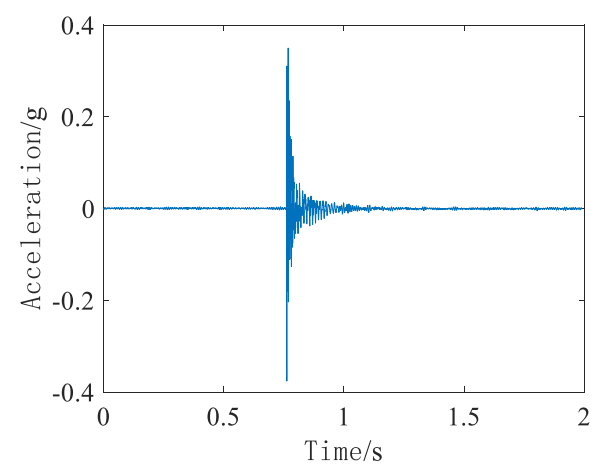

(b) Acceleration response signal

Figure 13 Excitation and acceleration response signal of the system

Based on the fast Fourier change algorithm, the acceleration response time-domain signal is analyzed in the frequency domain, and the power spectrum density of the system response is obtained as shown in Figure 14.

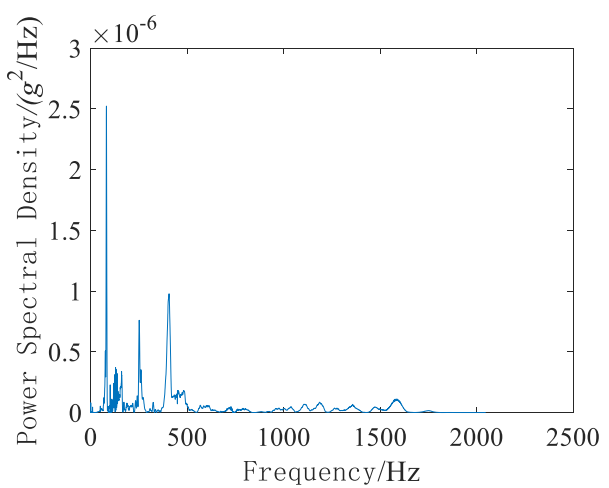

Figure 14 The power spectral density of the system response

It can be seen in Figure 14 that the power spectral density curves have peaks at $82.49 \mathrm{~Hz}, 258.5 \mathrm{~Hz}$ and $421.6 \mathrm{~Hz}$ respectively. Compare them with the theoretical values, the error between them is shown in Table 4. It can be seen that the maximum error between the theoretical value and the experimental value is $3.77 \%$, and the theoretical value is relatively close to the experimental value, which can verify the correctness of the theoretical analysis.

Table 4 Comparison of theoretical and experimental values of system natural frequency

\begin{tabular}{lccc}
\hline Experimental result & $\begin{array}{c}\text { Theoretical } \\
\text { value/Hz }\end{array}$ & $\begin{array}{l}\text { Experimental } \\
\text { value/Hz }\end{array}$ & error/\% \\
\hline First-order natural frequency & 82.49 & 81.87 & 0.76 \\
Second-order natural frequency & 258.5 & 251.6 & 2.74 \\
Third-order natural frequency & 421.6 & 406.3 & 3.77 \\
\hline
\end{tabular}

The error between the theoretical value and the experimental value may be caused by the following reasons: (1) the deviation in the estimated value of the parameters of the system, such as stiffness, quality; (2) the positive effect of the ignoring nonlinear characteristics of the system on the modal; (3) the nonstandard operation and the error of the sensor.

\section{Conclusions}

(1) Considering the equivalent stiffness and mechanicalhydraulic coupling characteristics of the opposing hydraulic cylinder controlled by servo valve, based on the relationship between the dynamic bulk modulus of oil and the dynamic equivalent stiffness of oil in each chamber, the free vibration dynamic model and equations of the system is established by using the lumped parameter method. The modal analysis of the system has been completed and the natural frequencies and main vibration modes of the system have been determined.

(2) The sensitivity analysis of the system is carried out. Within the variation range of the design parameters, the parameters that affect the first-order natural frequency of the system from strong to weak are the load mass, the equivalent mass of the moving part of the steering gear cylinder, the equivalent mass of the moving part of the loading cylinder, the connection stiffness and the equivalent stiffness of oil. The parameters that affect the second-order natural frequency of the system from strong to weak are the equivalent mass of the moving part of the loading cylinder, the load mass, the connection stiffness, the equivalent stiffness of oil, and the equivalent mass of the movement part of the steering gear cylinder. The parameters that affect the third-order natural frequency of the system from strong to weak are the equivalent mass of the movement part of the steering gear cylinder, the load mass, the equivalent mass of the movement part of the loading cylinder, the connection stiffness and the equivalent stiffness of oil.

(3) The dynamic experiment platform of the opposing hydraulic cylinder controlled by servo valve is built and the modal experiment is carried out. The theoretical modal frequency is close to the experimental modal frequency, and the maximum error is $3.77 \%$, which verifies the correctness of the dynamic theoretical model of the system. 


\section{Declaration}

\section{Acknowledgements}

Not applicable

\section{Funding}

Supported by Key Technologies Research and Development Program (Grant No.2019YFB2005302).

\section{Availability of data and materials}

The datasets supporting the conclusions of this article are included within the article.

\section{Authors' contributions}

\section{Competing interests}

The authors declare no competing financal interests.

\section{Consent for publication}

Not applicable

\section{Ethics approval and consent to participate}

Not applicable

\section{References}

[1] C H Jing, H G Xu, J H Jiang. Dynamic surface disturbance rejection control for electro-hydraulic load simulator. Mechanical Systems and Signal Processing, 2019, 134: 1-14.

[2] Tomonori Kato, Y W Xu, Tomohiro Tanaka, Kohei Shimazaki. Force control for ultraprecision hybrid electric-pneumatic verticalpositioning device. International Journal of Hydromechatronics, 2021, 1(1): 1 .

[3] S Kang, R Nagamune, H Yan. Almost disturbance decoupling force control for the electro-hydraulic load simulator with mechanical backlash. Mechanical Systems and Signal Processing, 2020, 135: 129.

[4] C Q Liu, Y F Jiang, Z Z Zhang, et al. Research on electro-hydraulic servo system of air rudder on model reference adaptive control. Journal of physics. Conference Series, 2020, 1650(2): 1-9.

[5] M J Li, J H Wei, J H Fang, et al. Fuzzy impedance control of an electro-hydraulic actuator with an extended disturbance observer. Frontiers of Information Technology \& Electronic Engineering, 2019, 20(9): 1221-1233.

[6] H K Wang and P G Leancy. Modelling and energy efficiency analysis of a hybrid pump-controlled asymmetric (single-rod) cylinder drive system. International Journal of Hydromechatronics, 2020, 3(1): 125 .

[7] J S Zhao, G Shen, C F Yang, et al. A robust force feed-forward observer for an electro-hydraulic control loading system in flight simulators. ISA Transactions, 2019, 89:198-217.

[8] C H Jing, H G Xu, J H Jiang. Practical torque tracking control of electro-hydraulic load simulator using singular perturbation theory. ISA Transactions, 2020, 102: 304-313

[9] H L Lv, X J Zhou, C L Yang, et al. Research on the modeling, control, and calibration technology of a tracked vehicle load simulation test bench. Applied Sciences, 2019, 9(12): 1-27.

[10] X M Yuan, X Zhu, C Wang, et al. Research on the dynamic behaviors of the jet system of adaptive fire-fighting monitors. Processes, 2019, 7(12): 1-18.

[11] J R Gevinski and R Pederiva. Prediction of dynamic strain using modal parameters. Journal of the Brazilian Society of Mechanical Sciences and Engineering, 2016, 38(1): 49-57.

[12] Y C Zhu and S K Au. Bayesian data driven model for uncertain moda properties identified from operational modal analysis. Mechanical Systems and Signal Processing, 2020, 136.

[13] C O Zhi, C T Hong, A Brandt, et al. An inconsistent phase selection assessment for harmonic peaks elimination in operational modal testing. Archive of Applied Mechanics, 2019, 89(12): 2415-2430.

[14] J H Yang, Lam H Fand, James L Beck. Bayes-Mode-ID: A Bayesian modal-component-sampling method for operational modal analysis. Engineering Structures, 2019, 189: 222-240.

[15] H Chen, C H Lu, Z E Liu, et al. Structural modal analysis and optimization of SUV door based on response surface method. Shock and Vibration, 2020, 2020

[16] P G Golano, L Z Fragonara, P Morantz,, et al. Numerical and experimental modal analysis applied to an optical test system designed for the form measurements of metre-scale optics. Shock and Vibration, 2018, 2018.

[17] S N Huang and A P Wang. Finite element analysis of space science experimental equipment based on hypermesh and nastran. MATEC Web of Conferences, 2018, 198

[18] T Wang, O Celik, F N Catbas, et al. A frequency and spatial domain decomposition method for operational strain modal analysis and its application. Engineering structures, 2016, 114(1): 104-112

[19] I Zaghbani, V Songmene. Estimation of machine-tool dynamic parameters during machining operation through operational modal analysis. International journal of machine tools \& amp; manufacture, 2009, 49(12): 947-957.

[20] S N Huang, A P Wang. Finite element analysis of space science experimental equipment based on hyperMesh and nastran. MATEC Web of Conferences, 2018, 198.

[21] F Bin Zahid F, Ong, Z C, Khoo S Y. A review of operational modal analysis techniques for in-service modal identification. Journal of the Brazilian Society of Mechanical Sciences and Engineering, 2020, 42(8): 1-18.

[22] B H Kim, N Stubbs, T Park. A new method to extract modal parameters using output-only responses. Journal of Sound and Vibration, 2004, 282(1): 215-230

[23] G James, T G Carne, J P Laufer. The natural excitation technique 
(NExT) for modal parameter extraction from operating structures. The International journal of analytical and experimental modal analysis, 1995, 10(4): 260

[24] P Andersen, H P Kirkegaard. Statistical damage detection of civil engineering structures using ARMAV models. Proceedings of SPIEThe International Society for Optical Engineering, 1998.

[25] Mikota, Gudrun. Modal analysis of hydraulic pipelines. Journal of Sound \& Vibration, 2013, 332(16): 3794-3805.

[26] G Mikota, B Manhartsgruber, H Kogler, et al. Modal testing of hydraulic pipeline systems. Journal of Sound \& Vibration, 2017, 409: 256-273.

[27] H Z Jiang, Z Z Tong, J F He, et al. Modal control of a hydraulically driven redundant actuated fully parallel mechanism. Journal of Vibration \& Control, 2017.

[28] D Cekus, B Posiadala. Vibration model and analysis of three-member telescopic boom with hydraulic cylinder for its radius change. International Journal of Bifurcation and Chaos, 2011, 21(10): 28832892.

[29] C G Hnanunni, R S Raj, D Nandan, et al. Sensitivity-based damage detection algorithm for structures using vibration data. Journal of Civil Structural Health Monitoring, 2019, 9(9).

[30] Chen L, Zhang X, Yan Z, et al. Matching model of dual mass flywheel and power transmission based on the structural sensitivity analysis method. Symmetry 2019;11(2).

[31] X M Yuan, X Zhu, C Wang, et al. Natural frequency sensitivity analysis of fire-fighting jet system with adaptive gun head. Processes, 2019, 7(11): 1-23.

[32] Z Zhang, C Zhou, W Wang, et al. Optimization design of aeronautical hydraulic pipeline system based on non-probabilistic sensitivity analysis. Journal of Risk and Reliability, 2019, 233.

[33] X D Kong, B Yu, L X Quan, et al. Nonlinear mathematical modeling and sensitivity analysis of hydraulic drive unit. Chinese Journal of Mechanical Engineering, 2015.

[34] X D Kong, K X Ba, B Yu, et al. Trajectory sensitivity analysis of first order and second order on position control system of highly integrated valve-controlled cylinder. Journal of Mechanical Science and Technology, 2015, 29(10): 4445-4464.

[35] W Wang, C Zhou, H Gao, et al. Application of non-probabilistic sensitivity analysis in the optimization of aeronautical hydraulic pipelines. Structural \& Multidisciplinary Optimization, 2017.
[36] X M Yuan, X Zhu, C Wang, et al. Research on theoretical model of dynamic bulk modulus of gas-containing hydraulic Oil. IEEE Access, 2019, 7: 178413-178422.

\section{Biographical notes}

Xiao-Ming Yuan, born in 1984, is currently a professor at Yanshan University, China. He received his Ph.D. degree from Yanshan University, Qinhuangdao, China, in 2014. His research interests include fluid-structure interaction dynamics of fire-fighting monitor, fluid transmission and control, and new magnetic gear transmission and control.

Tel: +86-13780560557; E-mail: xiaomingbingbing@163.com

Wei-qi Wang, received the B.S. degree from the School of Mechanical Engineering, Yanshan University, China, in 2020, where he is currently pursuing the master's degree. His research interests include fluid transmission and control, and fluid system simulation.

E-mail: wang0505204@163.com

Xuan Zhu, received the B.S. degree from the School of Mechanical Engineering, Yanshan University, China, in 2018, where he is currently pursuing the master's degree. His research interests include fluid transmission and control, and fluid system simulation.

E-mail: zx00712@126.com

Bing Du, born in 1985, is currently a professor at Yanshan University, China. She received her Ph.D. degree from Yanshan University,

China, in 2014. Her research interests include material forming process and theory.

E-mail: pangpang115@ysu.edu.cn

Li-jie Zhang, born in 1969, is currently the vice-chancellor at Hebei Agricultural University, China. He received his Ph.D. degree from Yanshan University, China, in 2006. His research interests include reliability and fault diagnosis of hydraulic components, multiphysics coupling analysis, and mechanics and robotics.

E-mail:ljzhang@ysu.edu.cn 